\title{
Association between hyperuricemia, prediabetes, and prehypertension in the Croatian adult population - a cross-sectional study
}

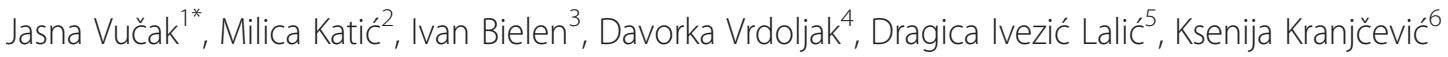
and Biserka Bergman Marković

\begin{abstract}
Background: The association between hyperuricemia, hypertension, and diabetes has been proved to have strong association with the risk for cardiovascular diseases, but it is not clear whether hyperuricemia is related to the early stages of hypertension and diabetes. Therefore, in this study we investigated the association between hyperuricemia, prediabetes, and prehypertension in Croatian adults, as well as that between purine-rich diet and hyperuricemia, prediabetes, or prehypertension.

Methods: A stratified random representative sample of 64 general practitioners (GP) was selected. Each GP systematically chose participants aged $\geq 40$ year (up to 55 subjects). Recruitment occurred between May and September 2008. The medical history, anthropometric, and laboratory measures were obtained for each participant.

Results: 59 physicians agreed to participate and recruited 2485 subjects (response rate 77\%; average age ( \pm standard deviation) $59.2 \pm 10.6 ; 61.9 \%$ women. In bivariate analysis we found a positive association between hyperuricemia and prediabetes (OR 1.66, 95\% Cl 1.09-2.53), but not for prehypertension (OR 1.68, 95\% Cl 0.76-3.72). After controlling for known confounders for cardiovascular disease (age, gender, body mass index, alcohol intake, diet, physical activity, waist to hip ratio, total cholesterol, low density lipoprotein, high density lipoprotein, and triglycerides), in multivariate analysis $\mathrm{HU}$ ceased to be an independent predictor(OR 1.33, Cl 0.98-1.82, $\mathrm{p}=0.069$ ) for PreDM. An association between purine-rich food and hyperuricemia was found $(p<0.001)$ and also for prediabetes $(p=0.002)$, but not for prehypertension ( $p=0.41$ ). The prevalence of hyperuricemia was $10.7 \%$ (15.4\% male, $7.8 \%$ female), 32.5\% for prediabetes (35.4\% male, 30.8\% female), and 26.6\% for prehypertension (27.2\% male, $26.2 \%$ female).
\end{abstract}

Conclusion: Hyperuricemia seems to be associated with prediabetes but not with prehypertension. Both, hyperuricemia and prediabetes were associated with purine-rich food and patients need to be advised on appropriate diet.

Trial registration: Current Controlled Trials ISRCTN31857696

Keywords: Hyperuricemia, Prediabetes, Prehypertension, Purine-rich food, Prevalence

\footnotetext{
* Correspondence: jasna.vuchak@zd.t-com.hr

'Family Health Center, Ambulanta, Ulica XVIII Sukosan, Zadar 23206, Croatia

Full list of author information is available at the end of the article
} 


\section{Background}

A large number of studies have linked hyperuricemia (HU) with hypertension, cardiovascular disease, and diabetes [1,2]. An association was shown between elevated concentrations of serum uric acid (SUA) and increased mortality in patients with myocardial infarction, heart failure, stroke, and other diseases [3,4] and also with a purine-rich diet, alcohol intake, and a number of cardiovascular disease (CVD) risk factors [5].

Experimental models have demonstrated that an elevated concentration of serum uric acid (SUA) increases blood pressure without affecting the morphology of the kidney [6], and that lowering uric acid can normalize blood pressure [7]. In addition to the association between SUA and hypertension, many authors have confirmed the correlation between SUA and development of type 2 diabetes [8]. The results showed that every increase of serum uric acid by $59.5 \mu \mathrm{mol} / \mathrm{L}$ results in a $60 \%$ increase in risk for developing diabetes [9]. Although there is unquestionable evidence of the association between uric acid and oxidative stress, endothelial dysfunction, inflammation, subclinical atherosclerosis, and cardiovascular disease there is no consensus regarding its value as an independent risk factor $[10,11]$.

Consequently, if hyperuricemia contributes to hypertension and diabetes, the assumption is that it should also contribute to prehypertension (PreHT) and prediabetes (PreDM). While hyperuricemia's relationship with hypertension and diabetes has been well studied, few studies dealt with the relationship between hyperuricemia and PreHT [12,13], and PreDM [14]. The aim of our study is to assess whether SUA level is associated with PreHT and/or PreDM in an adult population in a Croatian primary care setting.

\section{Methods}

\section{Study design}

The survey was conducted between May 2008 and July 2008 within a representative, random sample of general practitioners (GP), who were enrolled by a random number generator based on a list of all registered family medicine practices (2374 in total) from the Croatian Institute for Health Insurance. Stratification of GP's was made by region (coastal or continental), county (Croatia is divided into 21 counties), settlement size (up to 3999 inhabitants, 4000 to 9999, 10000 to 29 999, 30000 to 89 999, and 90 000 inhabitants and more), and number of insured patients based on a list of all GP's/family medicine practices having a contract with the Croatian Institute for Health Insurance (national compulsory health insurance system covering $97 \%$ of the population) in 2007.

Taking into consideration the available data for the prevalence of risk factors for cardiovascular diseases in Croatia, and the expected dispersion of examined persons (20\%), we determined that each GP should examine 55 patients $(80 \%$ power, alpha 0.05, G*Power for Windows 3.1.3).

The research was carried out within the randomised clinical trial Cardiovascular Risk and Intervention Study in Croatia-family medicine (CRISIC- $\mathrm{fm}$ ), and was registered as a clinical trial (Current Controlled Trials ISRCTN31857696).

The study was approved by the Ethics Committee of Zagreb University School of medicine.

\section{Participants}

Each general practitioner (GP) enrolled a consecutive, representative sample of participants aged $\geq 40$ years (up to 55 subjects), who visited the practice from May 2008 to July 2008 who meet the criteria and provided informed consent to participate. The exclusion criteria included communication disability (dysphasia, aphasia), severe dementia or mental illness, and disease with an estimated life expectancy of less than six months.

All GP received precise instruction to enrol two patients per day between $10 \mathrm{am}$ and $11 \mathrm{am}$ during their morning shift, and between $4 \mathrm{pm}$ and $5 \mathrm{pm}$ during their afternoon shift.

The interviews and two questionnaires that contained 140 and 127 items, respectively, were used to collect the socio-demographic, socio-economic, personal and family history data, and also information on the dietary and living habits, physical activity, medical therapy, psychological aspects and environment of the participants. The first questionnaire was administered and the anthropometric measurements were taken on the first day by the GP and the second questionnaire was given to patients to complete at home and return the following week when they arrive at the surgery for blood sampling after a minimum 8-hour fast.

\section{Measurement}

All subjects were measured twice for height and weight (using identical standardised anthropometric scales), waist and hip circumference (by plastic coated, nonelastic centimetre tape), blood pressure (by mercury sphygmomanometer), and pulse rate. Data on smoking were obtained by self-assessment (smokers, former smokers who stopped smoking $>6$ months, and nonsmokers). Moderate drinking was defined as $20 \mathrm{~g}$ ethanol per day for men and $10 \mathrm{~g}$ for women and the data were obtained by self-assessment. Overweight was defined as BMI $\geq 25$ and obesity as BMI $\geq 30$. Hypertension was defined as $\geq 140$ systolic and/or $\geq 90$ diastolic, or the use of antihypertensive drugs [15]. Diabetes mellitus was defined as fasting plasma glucose $\geq 7.0 \mathrm{mmol} / \mathrm{L}$, or the use of hypoglycaemic drugs. Serum uric acid (SUA), fasting blood glucose (FBG), total cholesterol (TC), high density lipoprotein cholesterol (HDL), low density 
lipoprotein cholesterol (LDL), triglycerides (TG), creatinine, complete blood count, and complete urine analysis were performed. Hyperuricemia (HU) was defined as serum uric acid concentration $\geq 420 \mu \mathrm{mol} / \mathrm{L}$ in men and $\geq 360 \mu \mathrm{mol} / \mathrm{L}$ in women. PreHT was determined using JNC7 [16] definition, and considered to be blood pressure readings based on the average of 2 or more properly measured, seated BP readings on each of 2 or more office visits with a systolic pressure from 120 to $139 \mathrm{~mm} \mathrm{Hg}$ or a diastolic pressure from 80 to $89 \mathrm{~mm}$ Hg. PreDM was determined using the criteria from the American Diabetes Association [17] with fasting plasma glucose level from $5.6 \mathrm{mmol} / \mathrm{L}$ to $6.9 \mathrm{mmol} / \mathrm{L}$.

For dietary habits, the subjects were divided into 4 groups according to the frequency of purine-rich food consumption [18]. The first group comprised of subjects with a total of $0-5$ points, the second $6-10$ points, the third 11-15 points, and the fourth $16-20$ points. The scoring is shown in Table 1.

\section{Statistical analysis}

The basic characteristics of the sample were described by descriptive statistics. The differences between the categorical variables with relative risk for PreDM and PreHT were analyzed using the chi-square test. Logistic regression analysis was used to examine which variables were statistically significant risk factors in certain groups in relation to and adjusted for the relevant confounders using bivariate analysis. All values were interpreted according to a significance level of 95\% (CI 95\%, P < 0.05). All statistical methods were performed using SPSS for Windows (19.0.0.1, SPSS Inc., Chicago, Illinois, 2011).

\section{Results}

Fifty-nine physicians recruited a total of 2485 subjects (response rate $77 \%$ ). There were $61.9 \%$ women (mean age ( \pm standard deviation) $58.9 \pm 10.5$ ) and $38.1 \%$ men (mean age $59.5 \pm 10.7$ ). Their basic characteristics are shown in Table 2.

Hyperuricemia prevalence in the observed population was $10.7 \%$ (240) (men $15.4 \%$, women $7.8 \%$ ), and was more frequent in men $\left(\mathrm{x}^{2}=33.6, \mathrm{p}<0.001\right)$. Although
Table 2 Basic characteristics of the study population

\begin{tabular}{|c|c|}
\hline Characteristic & Total \\
\hline$($ mean \pm SD); n (\%) & $\mathrm{N}=\mathbf{2 4 8 5}$ \\
\hline Age(years) & $59.2 \pm 10.6$ \\
\hline $\mathrm{BMI}, \mathrm{kg} / \mathrm{m}^{2}$ & $28.9 \pm 4.9$ \\
\hline Waist/hip ratio & $0.9 \pm 0.1$ \\
\hline Total cholesterol (TC) mmol/L & $5.8 \pm 1.2$ \\
\hline Low density lipoprotein cholesterol (LDL-C) mmol/L & $3.5 \pm 1.08$ \\
\hline High density lipoprotein cholesterol (HDL-C) mmol/L & $1.5 \pm 0.4$ \\
\hline Fasting blood glucose (FBG) mmol/L & $6.0 \pm 2.3$ \\
\hline Triglyceride (TG) mmol/L & $1.9 \pm 1.4$ \\
\hline Systolic blood pressure (SBP) $\mathrm{mmHg}$ & $131.4 \pm 17.0$ \\
\hline Diastolic blood pressure (DBP) $\mathrm{mmHg}$ & $80.7 \pm 9.2$ \\
\hline Serum uric acid (SUA) $\mu \mathrm{mol} / \mathrm{L}$ & $287.7 \pm 99.5$ \\
\hline Smoking, n (\%) & $539(22.4 \%)$ \\
\hline Physically active, n (\%) & $1254(56.0 \%)$ \\
\hline Hyperuricemia, n (\%) & $240(10.7 \%)$ \\
\hline Prehypertension (PreHT), n (\%) & $595(26.6 \%)$ \\
\hline Prediabetes(PreDM), n (\%) & $729(32.5 \%)$ \\
\hline Alopurinol use, n (\%) & $64(2.9 \%)$ \\
\hline
\end{tabular}

Smoking - actual smoking or less than 6 months since quitting.

Physically active - at least $150 \mathrm{~min} /$ week moderate to vigorous physical activity. Hyperuricemia ( $\geq 420 \mu \mathrm{mol} / \mathrm{L}$ men, $\geq 360 \mu \mathrm{mol} / \mathrm{L}$ women).

Prehypertension PreHT (SBP 120-139 mmHg and/or DBP 80-89 mmHg).

Prediabetes PreDM (fasting blood glucose 5.6-6.9 mmol/L).

the prevalence of hyperuricemia was equal in men and women over 60 years of age, treatment with allopurinol was more frequent in men $\left(X^{2}=28.1, \mathrm{p}<0.001\right)$.

The prevalence of PreHT was 26.6\% (595) (men 27.2\%, women 26.2) and of PreDM was $32.5 \%$ (729) (men $35.4 \%$, women $30.8 \%$ ).

The average values of SUA in men who had PreHT and PreDM did not differ relative to normotensive/nondiabetic man $(t=1.67, p=0.097)$. In contrast, women with PreHT/PreDM have higher averaged values of SUA $(\mathrm{t}=3.37, \mathrm{p}=0.001)$.

Bivariate analysis showed that hyperuricemia was significantly associated with PreDM (OR 1.71, CI 1.292.28, $\mathrm{p}<0.001$ ) but not with PreHT in men (OR 1.75,

Table 1 Scoring of purine-reach food consumption

\begin{tabular}{llllll}
\hline & Everyday & $\begin{array}{l}\text { Few times a week } \\
\text { but not everyday }\end{array}$ & Once a week & Once a month & $\begin{array}{c}\text { Never or less } \\
\text { than a month }\end{array}$ \\
\hline Red meat and red meat products & 4 & 3 & 2 & 1 & 0 \\
Wine and/or beer & 4 & 3 & 2 & 1 & 0 \\
Liquor & 4 & 3 & 2 & 1 & 0 \\
Sugar sweetened soft drinks (fructose) & 4 & 3 & 2 & 1 & 0 \\
Animal fat & 4 & 3 & & & 0 \\
Total & & &
\end{tabular}


Table 3 Odds ratio of PreDM and PreHT based on clinical variables

\begin{tabular}{|c|c|c|c|c|c|c|}
\hline \multirow[t]{2}{*}{ Variables } & \multicolumn{3}{|c|}{ Prediabetes } & \multicolumn{3}{|c|}{ Prehypertension } \\
\hline & OR & $95 \% \mathrm{Cl}$ & $\mathbf{p}$ & OR & $95 \% \mathrm{Cl}$ & $\mathbf{p}$ \\
\hline Female gender & 0.71 & $0.6-0.9$ & $<0.001$ & 0.79 & $0.63-1.03$ & 0.059 \\
\hline Age $\geq 60$ yrs & 1.17 & $0.99-1.40$ & 0.067 & 1.14 & $0.90-1.45$ & 0.273 \\
\hline Smoking & 0.72 & $0.57-0.90$ & 0.005 & 0.65 & $0.50-0.85$ & 0.002 \\
\hline Hyperuricemia ( $\geq 420 \mathrm{~m}$ i $\geq 360 \mathrm{f}$ ) & 1.71 & $1.29-2.28$ & $<0.001$ & 1.34 & $0.87-2.14$ & 0.180 \\
\hline BMl overweight $\left(25-29.9 \mathrm{~kg} / \mathrm{m}^{2}\right)$ & 1.41 & $1.11-1.79$ & 0.005 & 1.38 & $1.05-1.80$ & 0.020 \\
\hline BMl obese $\left(\geq 30 \mathrm{~kg} / \mathrm{m}^{2}\right)$ & 2.01 & $1.58-2.57$ & $<0.001$ & 1.34 & $0.99-1.79$ & 0.060 \\
\hline Waist-to-hip ratio (WHR) & 1.44 & $1.19-1.74$ & $<0.001$ & 1.16 & $0.91-1.47$ & 0.245 \\
\hline Pro-uric diet (score >10) & 1.61 & $1.25-2.06$ & $<0.001$ & 1.17 & $0.84-1.64$ & 0.393 \\
\hline Alcohol consumption & 1.3 & $1.06-1.58$ & $<0.001$ & 0.97 & $0.75-1.24$ & 0.848 \\
\hline Triglycerides (>1.7mmol/L) & 1.47 & $1.23-1.75$ & $<0.001$ & 1.27 & $1.01-1.60$ & 0.045 \\
\hline Total cholesterol (>5.0 mmol/L) & 1.09 & $0.86-1.30$ & 0.560 & 0.87 & $0.67-1.14$ & 0.365 \\
\hline HDL-cholesterol $(\mathrm{m}<1.03, \mathrm{f}<1.29 \mathrm{mmol} / \mathrm{L})$ & 1.24 & $0.99-1.56$ & 0.069 & 0.88 & $0.65-1.21$ & 0.440 \\
\hline LDL-cholesterol (>3.0 mmol/L) & 1.03 & $0.83-1.27$ & 0.829 & 0.84 & $0.63-1.11$ & 0.250 \\
\hline
\end{tabular}

Smoking - actual smoking or less then 6 months since quitting

Waist-to-hip ratio $-\mathrm{m}>0.9, \mathrm{f}>0.85$.

Pro-uric diet - according to Table 1.

Alcohol consumption $->20 \mathrm{~g}$ ethanol per day for men and $>10 \mathrm{~g}$ for women.

CI $0.70-2.39, \mathrm{p}=0.23$ ) and women (OR 1.75, CI 0.662.62, $\mathrm{p}=0.262$ ). Only BMI was a predictor for PreHT. The data are shown in Table 3. All significant bivariate findings were used in multivariate logistic regression models for PreDM and PreHT. After controlling for the impact of significant risk factors (gender, BMI status, alcohol intake, diet, smoking, and triglycerides) HU ceased to be a significant independent predictor (OR 1.33, CI 0.98-1.82, $\mathrm{p}=0.069$ ) for PreDM . For the PreHT group, only non-smoking habit was a significant predictor when controlled for BMI status, smoking, and triglycerides (OR 1.52, CI 1.16-1.99, $\mathrm{p}=0.03$ ).

Participants with a higher pro-uric food intake were obese $\left(\chi^{2}=14.01, \mathrm{p}=0.007\right)$ and had higher uric acid values $\left(\chi^{2}=10.29, \mathrm{p}=0.006\right)$. Participants with PreHT do not show significant differences in the frequency of prouric food intake, while participants with PreDM consume pro-uric food more often as it shown in Table 4.

\section{Discussion}

This study showed an association between hyperuricemia and prediabetes, whereas the association with prehypertension was questionable and significant only when associated with increased BMI and triglycerides. Furthermore, we found that BMI remained the only predictor for prehypertension, while hyperuricemia was a predictor for prediabetes when combined with BMI. This is compatible with the study of Ishizaka et al. proposing a correlation between SUA, BMI, and waist circumference [19]. The PreCIS study [20] has shown that uric acid levels are increased in patients with hypertension and diabetes, while we showed that this association also exists in patients with prediabetes, even when other risk factors for cardiovascular disease are excluded.

There are a number of studies associating oxidative stress with the development of diabetes mellitus and its complications [21]. Since SUA is one of the most powerful

Table 4 Relationship between purine-rich diet and HU, PreHT, PreDM, and BMI

\begin{tabular}{|c|c|c|c|c|c|c|}
\hline \multirow[t]{3}{*}{ Diet* $^{*}$} & \multirow[t]{3}{*}{ N (\%) } & \multirow{2}{*}{$\begin{array}{l}\mathrm{HU} \\
\mathrm{N}=228\end{array}$} & \multirow{2}{*}{$\begin{array}{l}\text { PreHTN } \\
\mathrm{N}=641\end{array}$} & \multirow{2}{*}{$\begin{array}{l}\text { PreDM } \\
\mathrm{N}=771\end{array}$} & \multirow{2}{*}{$\frac{\mathrm{BMI}(25-29.9)}{\mathrm{N}=994}$} & \multirow{2}{*}{$\begin{array}{l}\mathrm{BMI}(>30) \\
\mathrm{N}=834\end{array}$} \\
\hline & & & & & & \\
\hline & & $\mathrm{N}(\%)$ & $\mathrm{N}(\%)$ & $\mathrm{N}(\%)$ & $\mathrm{N}(\%)$ & N (\%) \\
\hline Score 0-4 & $873(37.4 \%)$ & $56(24.6 \%)$ & $223(34.8 \%)$ & $255(33.1 \%)$ & $373(37.5 \%)$ & $284(34.1 \%)$ \\
\hline Score 5-10 & 1156 (49.5\%) & $128(56.1 \%)$ & 327 (51.0\%) & $382(49.5 \%)$ & $490(49.3 \%)$ & $428(51.3 \%)$ \\
\hline Score 11-15 & $292(12.5 \%)$ & 43 (18.9\%) & 87 (13.6\%) & 127 (16.5\%) & 126 (12.7\%) & 116 (13.9\%) \\
\hline Score 16-20 & $13(0.6 \%)$ & $1(0.4 \%)$ & $4(0.6 \%)$ & 7 (0.9\%) & $5(0.9 \%)$ & $6(0.7 \%)$ \\
\hline$P^{* *}$ & & $<0.001$ & 0.406 & 0.002 & 0.200 & 0.009 \\
\hline
\end{tabular}

*frequency of pro-uric food intake according to Table 1.

$* * X^{2}$ test. 
water-soluble antioxidants, produced mainly by endothelial cells, there are speculations that high concentrations of SUA are the result of the body defensive mechanisms. On the other hand, norepinephrine infusions and/or angiotensin II lead to reversibly elevated blood pressure and SUA. In this context, a possible mechanism could be an increase in sympathetic activity leading to oxidative stress, and the body's effort to reduce damage using its most powerful antioxidant and to the breakdown of compensatory mechanisms. This is supported by studies that associated increases in norepinephrine level, blood pressure, and SUA with increased body mass and further hypertension progression [22].

It is known that uric acid clearance is inversely correlated with insulin resistance, which is the main pathophysiological factor of all metabolic syndrome (MS) components. There is some level of agreement that uric acid levels should be determined in MS patients because of the association with major cardiovascular risk, especially in woman [23]. This study shows that other components of metabolic syndrome (BMI, TG, and WHR) also play a significant role in prediabetes incidence in the presence of HU. Accordingly, the measurement of SUA should be introduced as an additional indicator of poor prognosis in patients with metabolic syndrome, which is in accordance with recent studies [24,25].

We found that HU prevalence in Croatian adults was $10.7 \%$ (15.4\% male, $7.8 \%$ female) and was lower than in other populations. This may be because the population only included subject of Caucasian origin. The lack of a relationship between hyperuricemia and prehypertension may be partly explained by the lower prevalence of hyperuricemia in the studied population than in other populations, where it ranges from $21.3 \%$ to $26.2 \%$ [26-28].

Sundström et al. [29] confirmed the independent effect of elevated uric acid levels on hypertension incidence and on its progression. Therefore a higher incidence of hyperuricemia is to be expected in prehypertensive patients, but our study did not show this. This implies that the progression from prehypertension to hypertension occurs through other mechanisms favored by the increased SUA or occurred in parallel with the increase, but is not caused by it. This conclusion is consistent with findings from a previous study by the same authors, who followed a subgroup for 12 years and observed the connection between uric acid levels and hypertension incidence disappeared. It is also in concordance with findings that allopurinol administration improves endothelial function but has no significant effect on systemic blood pressure in patients with type II diabetes and mild hypertension [30].

The prevalence of $\mathrm{HU}$ in women and men was similar in older age groups. Fang et al. found a strong relationship between increased UA and cardiovascular mortality among women [11], even after adjusting for diuretic use and menopausal status. Considering this fact, which was also demonstrated by our study, the relationship between $\mathrm{HU}$ and prehypertension is especially strong in postmenopausal women probably because they lose the uricosuric effect of estrogen. This may contribute to the increased risk of adverse cardiovascular events.

To the best of our knowledge, most previous studies have not been taken into account eating habits even though they could affect UA levels. We therefore sought to investigate further and divide the patients into 4 groups according to their dietary habits (consumption of purine rich-food). The obtained results continued to correlate $\mathrm{HU}$ with prehypertension and prediabetes in spite of differences in dietary habits.

\section{Strength and limitations of the study}

Strength: The large community based sample and adjustment for numerous potential confounders, including eating habits, of the studied population strengthen our investigation.

Limitations: It was a cross-sectional study and so the causal relationship between serum uric acid concentration with prediabetes and prehypertension cannot be evaluated.

\section{Conclusion}

Since prehypertension and prediabetes are pre-stages of hypertension and diabetes, respectively, it can be expected that $\mathrm{HU}$ will be more often present in persons suffering from prehypertension and/or prediabetes. We have proved that this is the case only with prediabetes and not with prehypertension. Purine-rich food is related with both, HU and prediabetes, and patients need to be advised on appropriate diet.

\section{Abbreviations}

HU: Hyperuricemia; SUA: Serum Uric Acid; CVD: Carddiovascular Disease: PreHT: Prehypertension; PreDM: Prediabetes; BMI: Body Mass Index; WHR: Waist To Hip Ratio; TC: Total Cholesterol; LDL: Low Density Lipoprotein Cholesterol; HDL: High Density Lipoprotein Cholesterol; TG: Triglycerides; GP: General Practitioner; FBG: Fasting Blood Glucose.

\section{Competing interests}

The authors have no conflict of interest to disclose related to this study.

\section{Authors' contributions}

$J V$ researched the data and wrote the manuscript, MK reviewed/edited the manuscript, IB contributed to the discussion and edited the manuscript, KK contributed to the discussion and edited the manuscript, DV contributed to the discussion and edited the manuscript, DIL contributed to the discussion and edited the manuscript, and BBM reviewed/edited the manuscript. All authors read and approved the final manuscript.

\section{Acknowledgments}

We thank Milan Milosevic for the statistical analysis of the data.

\section{Author details}

${ }^{1}$ Family Health Center, Ambulanta, Ulica XVIII Sukosan, Zadar 23206, Croatia. ${ }^{2}$ Department of Family Medicine, School of Medicine University of Zagreb, 
Zagreb, Croatia. 'Department of neurology, Hospital "Sveti Duh", Zagreb, Croatia. ${ }^{4}$ Department of Family Medicine, School of Medicine University of Split, Split, Croatia. ${ }^{5}$ Family Health Center, Novska, Croatia. ${ }^{6}$ Family Health Center, DZ Zapad, Zagreb, Croatia.

Received: 12 September 2012 Accepted: 29 November 2012 Published: 4 December 2012

\section{References}

1. Feig DI, Kang D, Johnson RJ: Uric acid and cardiovascular risk. N Engl J Med 2008, 359:1811-1821.

2. Chien KL, Chen MF, Hsu HC, Chang WT, Su TC, Lee YT, Hu FB: Plasma uric acid and risk of type 2 diabetes in Chinese community. Clin Chem 2008, 54(2):310-316

3. Holme I, Aastveit AH, Hammar N, Jungner I, Walldius G: Uric acid and risk of myocardial infarction, stroke and congestive heart failure in 417,734 men and women in the apolipoprotein MOrtality RISk study (AMORIS). J Intern Med 2009, 266(6):558-570.

4. Bos MJ, Koudstaal PJ, Hofman A, Witteman JCM, Bretler MMB: Uric acid is a risk factor for myocardial infarction and stroke: the Rotterdam study. Stroke 2006, 37:1503-1507.

5. Klein $B E$, Klein $R$, Lee KE: Components of the metabolic syndrome and risk of cardiovascular disease and diabetes in beaver Dam. Diabetes Care 2002, 25:1790-1794

6. Mazzali M, Hughes J, Kim YG, Jefferson A, Kang DH, Gordon KL, Lan HY, Kivlighn S, Johnson RJ: Elevated uric acid increases blood pressure in the rat by a novel crystal-independent mechanism. Hypertension 2001 38:1101-1106

7. Feig DI, Nakagawa T, Karumanchi SA, Oliver WJ, Kang DH, Finch J, Johnson RJ Hypothesis: uric acid, nephron number, and the pathogenesis of essential hypertension. Kidney Int 2004, 66:281-287.

8. Dehghan A, van Hoek M, Sijbrands EJG, Hofman A, Witteman JCM: High serum uric acid as a novel risk factor for type 2 diabetes. Diabetes Care 2008, 31(2):361-362.

9. Kramer CK, von Muhlen D, Jassal SK, Barrett-Connor E: Serum uric acid levels improve prediction of incident type 2 diabetes in individuals with impaired fasting glucose: the rancho Bernardo study. Diabetes Care 2009, 32(7):1272-1273.

10. Fang J, Alderman MH: Serum uric acid and cardiovascular mortality: the NHANES I epidemiologic follow-up study, 1971-1992. JAMA 2000, 283(18):2404-2410.

11. Culleton BF, Larson MG, Kannel WB, Levy D: Serum uric acid and risk of cardiovascular disease and mortality: the Framingham heart study. Ann Intern Med 1999, 31:7-13.

12. Syamala S, Li J, Shankar A: Association between serum uric acid and prehypertension among US adults. J Hypertens 2007, 25(8):1583-1589.

13. Liang J, Xue Y, Zou C, Zhang T, Song H, Qi L: Serum uric acid and prehypertension among Chinese adults. J Hypertens 2009, 27:1761-1765.

14. Bhole V, Choi JWJ, Kim SW, de Vera M, Choi H: Serum uric acid levels and the risk of type 2 diabetes: a prospective study. Am J Med 2010, 123(10):957-961.

15. Graham I, Atar D, Borch-Johnsen K, Boysen G, Burell G, Cifkova R, Dallongeville J, De Backer G, Ebrahim S, Gjelsvik B, Herrmann-Lingen C, Hoes A, Humphries S, Knapton M, Perk J, Priori SG, Pyorala K, Reiner Z, Ruilope L, Sans-Menendez S, Scholte op Reimer W, Weissberg P, Wood D, Yarnell J, Zamorano JL, Walma E, Fitzgerald T, Cooney MT, Dudina A, European Society of Cardiology (ESC), Committee for Practice Guidelines (CPG): Fourth joint task force of the European society of cardiology and other societies on cardiovascular disease prevention in clinical practice. European guidelines on cardiovascular disease prevention in clinical practice: executive summary. Eur Heart J 2007, 28:2375-2414.

16. Chobanian AV, Bakris GL, Black HR, Cushman WC, Green LA, Izzo JL Jr, Jones DW, Materson BJ, Oparil S, Wright JT Jr, Rocellla EJ, National High Blood Pressure Education Program Coordinating Committee: Seventh report of the joint national committee on prevention, detection, evaluation, and treatment of high blood pressure. Hypertension 2003, 42(6):1206-1252.

17. Prediabetes FAQs: American diabetes association; 2012. http://www.diabetes. org/diabetes-basics/prevention/pre-diabetes/pre-diabetes-faqs.html. Accessed Jan. 29

18. Fam AG: Gout, diet, and the insulin resistance syndrome. J Rheumatol 2002, 29:1350-1355.
19. Ishizaka N, Ishizaka Y, Toda A, Tani M, Koike K, Yamakado M, Nagai R: Changes in waist circumference and body mass indeks in relation to changes in serum uric acid in Japanese individuals. J Rheumatol 2010, 37:410-416

20. Loachimescu AG, Brennan DM, Hoar BM, Hazen SL, Hoogwerf BJ: Serum uric acid is an independent predictor of all-cause mortality in patients at high risk of cardiovascular disease. Arthritis\&Rheumatism 2008, 58(2):623-630.

21. Baynes JW, Thorpe SR: Role of oxidative stress in diabetic complications a new perspective on an old paradigm. Diabetes 1999, 48:1-9.

22. Masuo K, Kawaguchi H, Mikami H, Ogihara T, Tuck ML: Serum uric acid and plasma norepinephrine concentrations predict subsequent weight gain and blood pressure elevation. Hypertension 2003, 42:474-480.

23. Kawamoto R, Tomita H, Oka Y, Ohtsuka N: Relationship between serum uric acid concentration, metabolic syndrome and carotid atherosclerosis. Intern Med 2006, 45(9):605-614.

24. Nakagawa T, Hu H, Zharikov S, Tuttle KR, Short RA, Glushakova O, Ouyang X, Feig DI, Block ER, Herrera-Acosta J, Patel JM, Johnson RJ: A causal role for uric acid in fructose-induced metabolic syndrome. Am J Physiol 2006, 290:625-631.

25. Hayden MR, Tyagi SC: Uric acid: a new look at an old risk marker for cardiovascular disease, metabolic syndrome, and type1 diabetes mellitus: the urate redox shuttle. Nutr Metab (Lond) 2004, 19(1):10.

26. Conen D, Wietlisbach V, Bovet P, Shamlaye C, Riesen W, Paccaud F, Burnier M: Prevalence of hyperuricemia and relation of serum uric acid with cardiovascular factors in a developing country. BMC Publ Health 2004:4-9. doi:10.11861471-2458-4-9.

27. Nan H, Qiao Q, Dong Y, Gao W, Tang B, Qian R, Tuomilehto J: The prevalence of hyperuricemia in a population of the coastal city of Qingdao. China. J Rheumatol 2006, 33:1346-1350.

28. Zhu Y, Pandya BJ, Choi HK: Prevalence of gout and hyperuricemia in the US general population: the national health and nutrition examination survey 2007-2008. Arthritis \& Rheumatism 2011, 63:3136-3141.

29. Sundström J, Sullivan L, D'Agostino RB, Levy D, Kannel WB, Vasan RS: Relations of serum uric acid to longitudinal blood pressure tracking and hypertension incidence. Hypertension 2005, 45:28-33.

30. Butler R, Morris AD, Belch JJF, Hill A, Struthers AD: Allopurinol normalizes endothelial dysfunction in type 2 diabetics with mild hypertension. Hypertension 2000, 35:746-751.

doi:10.1186/1471-2261-12-117

Cite this article as: Vučak et al:: Association between hyperuricemia, prediabetes, and prehypertension in the Croatian adult population - a cross-sectional study. BMC Cardiovascular Disorders 2012 12:117.

\section{Submit your next manuscript to BioMed Central and take full advantage of:}

- Convenient online submission

- Thorough peer review

- No space constraints or color figure charges

- Immediate publication on acceptance

- Inclusion in PubMed, CAS, Scopus and Google Scholar

- Research which is freely available for redistribution 